\title{
Theoretical study of the reaction mechanism $\mathrm{Ba}, \mathrm{Ti}, \mathrm{O}$ in the early growth of BTO thin films
}

\author{
Chun Yang ${ }^{1}$, XiaoQin Liang ${ }^{1}$, Ping Huang ${ }^{2}$ \\ ${ }^{1}$ College of Chemistry and Materials, Sichuan Normal University, Chendu, China \\ ${ }^{2}$ College of Physics and Electronic Engineering, Sichuan Normal University, Chendu, China
}

\author{
Email address: \\ chunyang_2000@263.net (Chun Yang)
}

\section{To cite this article:}

Chun Yang, XiaoQin Liang, Ping Huang. Theoretical Study of the Reaction Mechanism Ba, Ti, O in the Early Growth of BTO Thin Films. International Journal of Computational and Theoretical Chemistry. Vol. 2, No. 5, 2014, pp. 41-45. doi: 10.11648/j.ijctc.20140205.11

\begin{abstract}
We use the $\mathrm{DMol}^{3}$ program based on density functional theory(DFT) to clarify the processes of microcosmic reactions and the particle states in the early growth of $\mathrm{BaTiO}_{3}$ (BTO) thin films. This research is important for optimal preparation and structure control of BTO thin films. After designing and optimizing some possible intermediate states, we find that the molecules may serve as nucleation sites for $\mathrm{BTO}$ growth. This occurs by combining $\mathrm{TiO}_{2}$ with $\mathrm{BaO}$ molecules to form $\mathrm{BaTiO}_{3}$ with the $\mathrm{G}$ conformation, which is similar to a quarter of a BTO unit cell. By virtue of understanding these mechanisms, perovskite-structured BTO thin films are formed.
\end{abstract}

Keywords: Barium Titanate, Reaction Mechanism, Thin Films Growth, Density Functional Theory, Activation Energy

\section{Introduction}

A revolution is occurring in science and technology based on the recently developed ability to measure, manipulate, and organize matter on ferroelectric thin films. These thin films are widely exploited for microwave phase shifters and dynamic random access memory due to their advantageous physical properties (piezoelectricity, ferroelectricity, pyroelectricity, and photoelectricity - the latter is used in nonlinear optics). As a typical representative of the perovskite structure thin films, $\mathrm{BaTiO}_{3}$ thin films are used not only to make microelectronic devices, but also to develop ferroelectric/superconductor devices by combining them with superconducting thin films[13]. As a result, progress in understanding BTO thin films will have a very far-reaching impact.

Currently, $\mathrm{BaTiO}_{3}$ (BTO) and $\mathrm{SrTiO}_{3}$ (STO) thin films are prepared primarily by Laser Molecular Beam Epitaxy (LMBE), not only because it allows in situ monitoring, but also because the chemical composition of thin films can be controlled. Using LMBE to prepare BTO and STO thin films, $\mathrm{Li}$, et al[4-6] demonstrated the feasibility of unit cell migration with surface self-diffusion by in situ reflective high energy electron diffraction and atomic force microscopy. The experiments revealed "unit cell migration", which formed the basis for a growth model for films. In addition, they measured the activation energy of unit cell migration in BTO and STO thin films to be $0.29 \pm 0.01 \mathrm{eV}[4,5]$.
However, these experimental investigations are inadequate to describe physical chemistry data such as interface structure, adsorption, diffusivity, and particle trajectories in the growth of thin films. Additionally, experimental information is lacking regarding the formation of the BTO perovskite structure unit cell and the physicochemical processes involving $\mathrm{Ba}, \mathrm{Ti}$, and $\mathrm{O}$ atoms. Thus, developing a theoretical picture is very important for advancing research in this area. We had investigated possible reaction mechanisms in initial growth process of $\mathrm{SrTiO}_{3}$ (STO) by a first-principles calculation in previous research [7]. To this end, we present a first-principles calculation using density functional theory (DFT) $[8,9]$ to investigate both the possible combination reactions and the initial process of migration growth of BTO to the cell stage.

Regarding unit cell formation with $\mathrm{Ba}, \mathrm{Ti}$, and $\mathrm{O}$ microcosmic particles formed by flash evaporation in the unit cell migration growth of BTO thin films, we hypothesize two cases. The first is that $\mathrm{Ba}, \mathrm{Ti}$, and $\mathrm{O}$ atoms form intermediates $\left(\mathrm{O}_{2}, \mathrm{BaO}, \mathrm{BaO}_{2}, \mathrm{TiO}, \mathrm{TiO}_{2}\right)$ by colliding, after which the unit cell is formed. The second is the formation of a perovskite structure unit cell by direct deposition of $\mathrm{Ba}, \mathrm{Ti}$, and $\mathrm{O}$ atoms on the surface of the substrate.

This paper is organized as follows, a brief introduction about the calculation method shows in section 2, the main results and discussion of the paper are described in section 3 and the end of the paper is conclusion. 


\section{Methodology}

We use the local orbital density functional method $\mathrm{DMol}^{3}$ program[10,11], which evolved from a gas phase molecular method to a method that allows for state-of-the-art calculations on non-conducting and metallic solids[12,13]. We used the PW91 function of the Generalized Gradient Approximation[14,15] and convergence conditions with a large basis set and high accuracy to optimize each structure of this system. During the calculations, the wave function of the valence electrons is expanded using the Double Numeric Polarization basis set in DFT, which is similar to 6$311++\mathrm{G}^{* *}$ of Gaussian theory, but more precise. Its selfconsistent convergence precision is set above $10^{-6}$ a.u. The energy convergence accuracy reaches $10^{-5}$ a.u., and the convergence accuracy of grads and displacements surpassed $10^{-4}$ a.u. $/ \mathrm{nm}$ and $5 \times 10^{-4} \mathrm{~nm}$, respectively. In the $\mathrm{DMol}^{3}$ program, all the electrons of atoms with atomic number less than 21 are involved in the calculation. Thus, all the electrons of $\mathrm{O}$ atoms and the valence electrons of $\mathrm{Ba}$ and $\mathrm{Ti}$ atoms are treated explicitly, but the core electrons of $\mathrm{Ba}$ and $\mathrm{Ti}$ atoms are replaced with effective core potential approximations[15]. Besides, we chose the most accurate transient state (TS) search methods to obtain the TS structure, namely the complete linear synchronous transit and the complete quadratic synchronous transit[17,18]. The activation energy of reactions can then be obtained after analyzing the energy difference between the intermediate state and the TS[19,20]. Incidentally, the TS can be confirmed easily if it has a higher energy than that of the reactants or intermediates and if it exists only at an imaginary frequency[21-23].

\section{Results and Discussion}

Generally, in an atmosphere containing $\mathrm{Ba}, \mathrm{Ti}$, and $\mathrm{O}$ atoms, $\mathrm{Ba}$ and $\mathrm{Ti}$ are easily oxidized by $\mathrm{O}$ atoms of higher activity, so that $\mathrm{O}_{2}, \mathrm{BaO}, \mathrm{BaO}_{2}, \mathrm{TiO}, \mathrm{TiO}_{2}$, and $\mathrm{BaTiO}_{3}$ molecules are formed preferentially prior to formation of the unit cell. Based on our analysis, we present some reaction models and their initial conditions, assuming a vacuum and non-equilibrium states with high-density reactants.

\subsection{The Formation of Molecular $\mathrm{TiO}_{2}$}

In vacuum, $\mathrm{O}$ atoms and $\mathrm{O}_{2}$ molecules may oxidize $\mathrm{Ti}$ atoms to form $\mathrm{TiO}_{2}$ molecules. We present two models to describe this process. Model IA (IB) involves $\mathrm{O}$ atoms $\left(\mathrm{O}_{2}\right.$ molecules) reacting directly with $\mathrm{Ti}$ atoms to form $\mathrm{TiO}_{2}$ molecules.

Within Model IA, the stabilization energy $E_{s}=E_{T_{i O} O_{2}}-E_{T i}-2 E_{O}$ of the $\mathrm{TiO}_{2}$ molecule is $1,429.59$ $\mathrm{kJ} / \mathrm{mol}$, using the energies given in Table 1 . This reaction proceeds very easily because of the gradual reduction of the total energy. For model IB, however, the situation is more complicated. There are few $\mathrm{O}_{2}$ molecules in the vacuum, although some are formed when $\mathrm{O}$ atoms are vaporized by the laser. $\mathrm{Ti}$ atoms and $\mathrm{O}_{2}$ molecules may form $\mathrm{TiO}_{2}$ molecules upon colliding. In the process of $\mathrm{TiO}_{2}$ formation, we find a barrier with one unique imaginary frequency, implying that an activation energy is needed to overcome the barrier. To analyze the reaction mechanism that yields $\mathrm{TiO}_{2}$, we optimize the conformations of the reactants (Ti atoms and $\mathrm{O}_{2}$ molecules), resultant $\left(\mathrm{TiO}_{2}\right.$ molecules), intermediate state (M1), and transient state (TS1) and find the reaction channel shown in Figure 1.

Table 1. The energies for particles of BTO thin films in the early growth.

\begin{tabular}{llll}
\hline & Energy (kJ/mol) & & Energy $(\mathbf{k J} / \mathbf{m o l})$ \\
\hline $\mathrm{O}$ & -197073.44 & $\mathrm{Ti}$ & -153099.73 \\
$\mathrm{O}_{2}$ & -394760.13 & $\mathrm{TiO}_{2}$ & -548676.20 \\
$\mathrm{M} 1$ & -548267.41 & $\mathrm{TS} 1$ & -548255.60 \\
$\mathrm{Ba}$ & -66817.44 & $\mathrm{BaO}$ & -264463.67 \\
$\mathrm{M} 2$ & -528746.82 & $\mathrm{TS} 2$ & -528691.81 \\
\hline
\end{tabular}

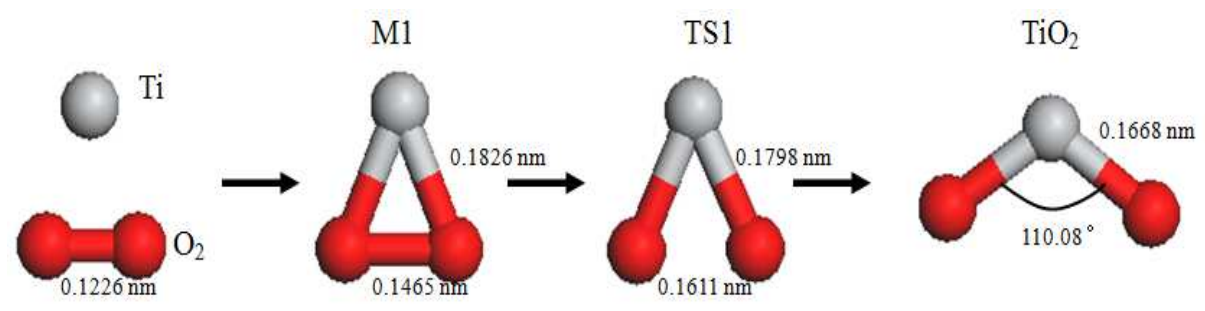

Fig. 1. The process of formation of molecular $\mathrm{TiO}_{2}$ (color online).

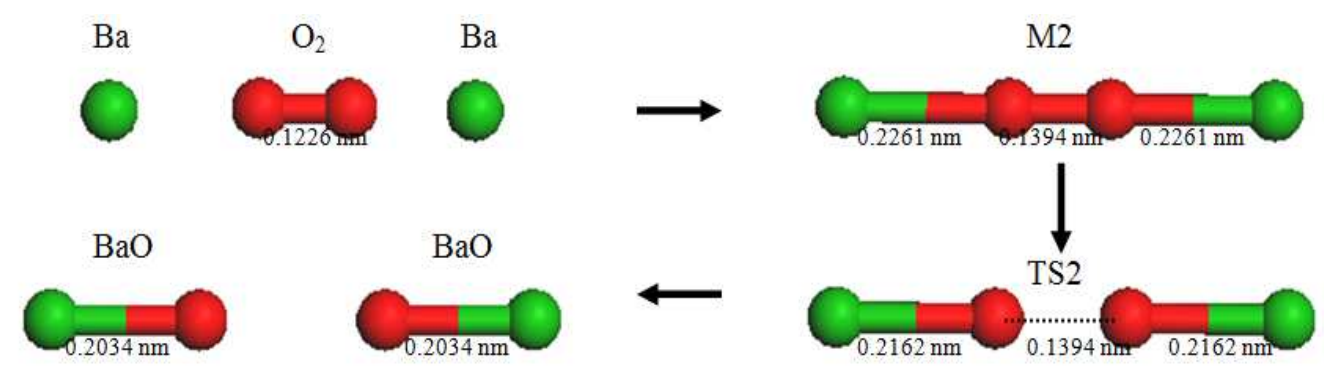

Fig. 3. The process of formation of molecular $\mathrm{BaO}$ (color online). 
$\mathrm{Ti}$ atoms form a coordination bond with the $\mathrm{O}_{2}$ lone-pair electrons, instantly (on the time scale of interest) transforming into an M1 compound. Due to the vibration of the O-O bond, $\mathrm{TiO}_{2}$ molecules form only after passage through the transient state TS1. We calculate that the energy of the reactants ( $\mathrm{Ti}$ atom and $\mathrm{O}_{2}$ molecule), intermediate state (M1), transient state (TS1), and resultant $\left(\mathrm{TiO}_{2}\right)$ is $547859.86 \mathrm{~kJ} / \mathrm{mol},-548267.41 \mathrm{~kJ} / \mathrm{mol},-548255.60 \mathrm{~kJ} / \mathrm{mol}$ and $-548676.20 \mathrm{~kJ} / \mathrm{mol}$, respectively, as shown in Fig. 2. From these values we find the stabilization energy M1 is $407.55 \mathrm{~kJ} / \mathrm{mol}$, and the activation energy $E_{A}=E_{T S 1}-E_{M 1}$ of formation of TS1 is $11.81 \mathrm{~kJ} / \mathrm{mol}$. The $\mathrm{O}-\mathrm{O}$ and Ti-O bond lengths and the $\mathrm{O}-\mathrm{Ti}-\mathrm{O}$ bond angles change during the formation of the $\mathrm{TiO}_{2}$ molecule, as shown in Fig. 1. This indicates that forming the Ti-O bonds weakens the $\mathrm{O}-\mathrm{O}$ bond in $\mathrm{M} 1$, so that it is easily broken, leading to the formation of $\mathrm{TiO}_{2}$ via the transient state TS1. The changes in bond lengths, bond angles, and stabilization energies thus lead us to conclude that the reaction always favors the formation of $\mathrm{TiO}_{2}$.

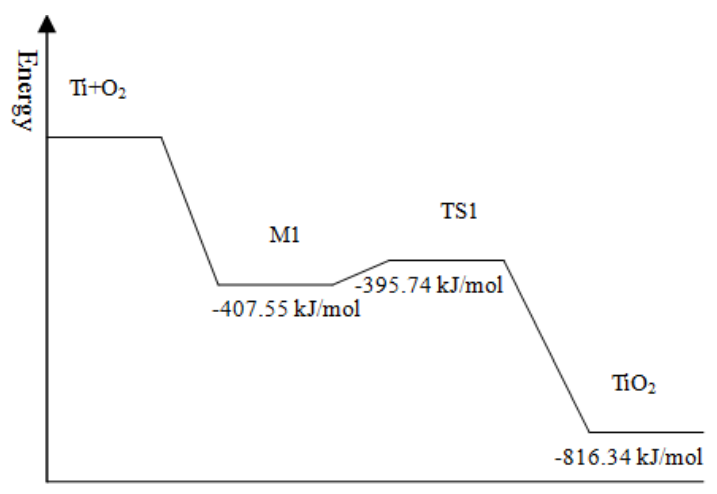

Fig. 2. The reaction energies of the formation of $\mathrm{TiO}_{2}$.

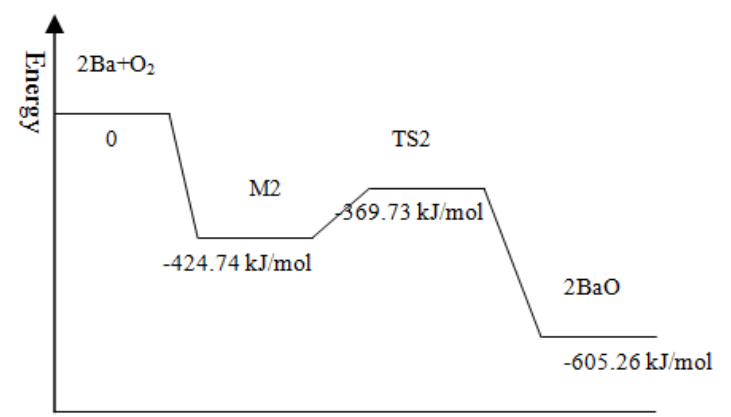

Fig. 4. The reaction energies of the formation of $\mathrm{BaO}$.

\subsection{The Formation of Molecular BaO}

The same analysis may be applied to $\mathrm{Ba}$ atoms, which are oxidized and form $\mathrm{BaO}$ molecules due to interactions with $\mathrm{O}$ atoms or $\mathrm{O}_{2}$ molecules. Here, we likewise use two models, model IIA (IIB) where the $\mathrm{Ba}$ and $\mathrm{O}$ atoms $\left(\mathrm{O}_{2}\right.$ molecule) interact to form $\mathrm{BaO}$. The reaction process is quite simple within model IIA - our calculation indicates that there is no energy barrier in this process. Using the energies given in Table 1, we find that the stabilization energy of the $\mathrm{BaO}$ molecule is $572.03 \mathrm{~kJ} / \mathrm{mol}$, which is consistent with values reported in the literature; i.e. $\mathrm{E}_{\mathrm{s}} \geq 562.8 \pm 14.6 \mathrm{~kJ} / \mathrm{mol}[24]$. In addition, the bond length of $\mathrm{BaO}$ is $0.2034 \pm 0.0053 \mathrm{~nm}[24]$.

Within model IIB, two Ba atoms form coordination bonds with the lone-pair electrons of an $\mathrm{O}_{2}$ molecule, instantly (on the time scale of interest) transforming into an M2 compound. The formation of the $\mathrm{Ba}-\mathrm{O}$ bond weakens the $\mathrm{O}-\mathrm{O}$ bond, and it is gradually broken resulting in the decomposition of M2 toward the $\mathrm{BaO}$ molecule via the transient TS2 state. By analyzed the transient TS2 state, we find that the stabilization energy of M2 is $424.74 \mathrm{~kJ} / \mathrm{mol}$ and that the activation energy of the reaction is $55.01 \mathrm{~kJ} / \mathrm{mol}$. These results imply that the reaction always favors the formation of $\mathrm{BaO}$ molecules.

\subsection{The Formation of Molecular BTO}

After $\mathrm{BaO}$ and $\mathrm{TiO}_{2}$ molecules are formed, they may interact to form $\mathrm{BaTiO}_{3} . \mathrm{BaO}, \mathrm{TiO}_{2}$, and $\mathrm{BaTiO}_{3}$ molecules, providing precursors for forming the $\mathrm{BTO}$ unit cell.

To be sure of the geometric conformations of $\mathrm{BaTiO}_{3}$, we built seven different possible structures according to the principle of molecular symmetry. As shown in Fig 5, after optimization of the seven structures, we find that the A, B, and $\mathrm{C}$ conformations are similar to the $\mathrm{F}$ conformation and that the $D$ and $E$ conformations are similar to the $G$ conformation. Furthermore, the system energies of the $\mathrm{F}$ and $\mathrm{G}$ conformations are the lowest, at $-813585.88 \mathrm{~kJ} / \mathrm{mol}$ and $813587.18 \mathrm{~kJ} / \mathrm{mol}$, respectively, indicating that these conformations are more stable.

To study the components and structures of BTO thin film crystals, we create a $2 \times 2$ BTO super-cell with four BTO molecules, corresponding to $\mathrm{BaTiO}_{3}$ molecules. The total energy of the super-cell is $-3257201.00 \mathrm{~kJ} / \mathrm{mol}$, and the average energy of the BTO molecule is $-814300.25 \mathrm{~kJ} / \mathrm{mol}$, making it 714.37 and $713.07 \mathrm{~kJ} / \mathrm{mol}$ less than the $\mathrm{F}$ and $\mathrm{G}$ conformations, respectively. In addition, we note that the most stable conformation, $\mathrm{G}$, is similar to a quarter-corner of the BTO unit cell, so that a BTO molecule with the G conformation, formed by $\mathrm{BaO}$ and $\mathrm{TiO}_{2}$ molecules, will be shaped into the BTO unit cell with a perovskite structure. Put another way, the G conformation, which is a BTO molecule, may be regarded as one component of a BTO unit cell.

To form a BTO molecule (see Figs. 6 and 7), the F conformation is first formed by collision between $\mathrm{BaO}$ and $\mathrm{TiO}_{2}$ molecules, which is a barrierless reaction. Immediately thereafter, the $\mathrm{Ba}$ atoms moves toward the center of the three $\mathrm{O}$ atoms until the $\mathrm{G}$ conformation is formed because of the attractive forces of the lone-pair electrons of the three $\mathrm{O}$ atoms. This process involves a barrier. Upon optimization and frequency analysis, we find a new transient state TS3. The characteristic parameters of TS3 are given in Table 2, and indicate that the reaction favors the $\mathrm{G}$ conformation and that it occurs easily due to the low activation energy (10.55 $\mathrm{kJ} / \mathrm{mol}$ ).

Our calculation and optimization indicate that there is little probability that $\mathrm{Ba}, \mathrm{Ti}$, and $\mathrm{O}$ atoms form a $\mathrm{BTO}$ unit cell directly but that some intermediates (such as $\mathrm{BaO}, \mathrm{TiO}_{2}$, and 
BTO molecules) need to be formed beforehand. The activation energies for the formation processes of $\mathrm{BaO}, \mathrm{TiO}_{2}$, and BTO are $55.01 \mathrm{~kJ} / \mathrm{mol}, 11.81 \mathrm{~kJ} / \mathrm{mol}$, and $10.55 \mathrm{~kJ} / \mathrm{mol}$, respectively, with the lower value indicating that the reaction occurs more easily.

Table 2. The differences between F, G conformations and BTO molecule on the atomic structures.

\begin{tabular}{|c|c|c|c|c|c|c|c|c|c|c|}
\hline & \multicolumn{3}{|c|}{ Bond length (nm) } & \multicolumn{3}{|c|}{ Bond angle $\left({ }^{\circ}\right)$} & \multicolumn{3}{|c|}{ The distance from $\mathrm{Ba}$ to $\mathrm{O}(\mathrm{nm})$} & \multirow{2}{*}{ Energy (kJ/mol) } \\
\hline & O1-Ti & O2-Ti & O3-Ti & O1-Ti-O2 & O2-Ti-O3 & O3-Ti-O1 & Ba-O1 & Ba-O2 & Ba-O3 & \\
\hline F conformation & 0.1831 & 0.1841 & 0.1679 & 95.7 & 112.2 & 111.3 & 0.2367 & 0.2362 & 0.4171 & -813585.88 \\
\hline TS3 & 0.1814 & 0.1816 & 0.1703 & 96.3 & 101.8 & 101.9 & 0.2406 & 0.2396 & 0.3193 & -813575.33 \\
\hline G conformation & 0.1779 & 0.1779 & 0.1779 & 96.8 & 96.8 & 96.8 & 0.2522 & 0.2522 & 0.2522 & -813587.18 \\
\hline BTO unit cell & 0.2015 & 0.2015 & 0.2015 & 90.0 & 90.0 & 90.0 & 0.2849 & 0.2849 & 0.2849 & -814300.25 \\
\hline
\end{tabular}

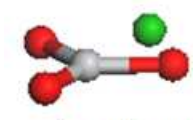

A conformation

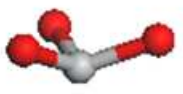

Econformation

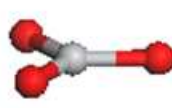

B conformation

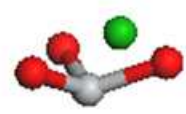

F conformation

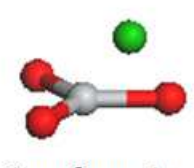

C conformation

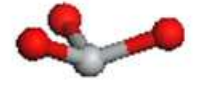

G conformation
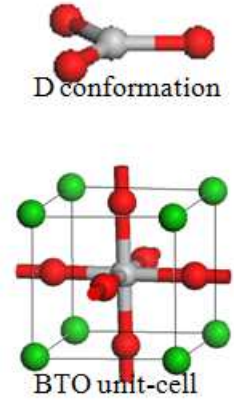

Fig. 5. The conformations of BTO molecule and the structure of BTO unit cell (color online).

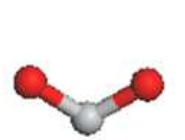

$\mathrm{TiO}_{2}$

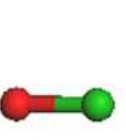

$\mathrm{BaO}$

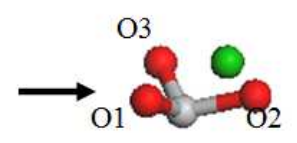

F conformation

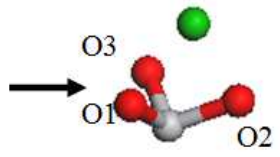

TS3

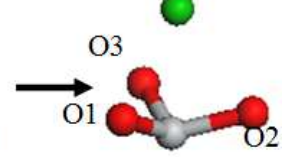

G conformation

Fig. 6. The process of formation of BTO molecule (color online).

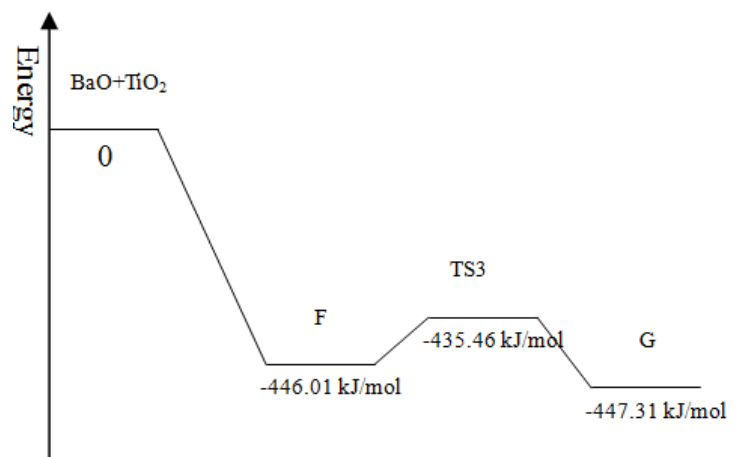

Fig. 7. The reaction energies of formation of BTO molecule.

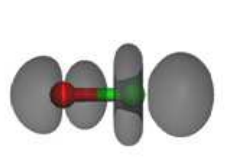

(a)

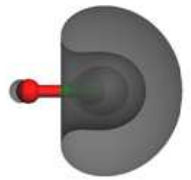

(b)

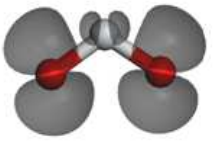

(c)

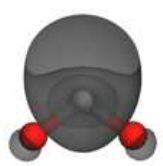

(d)

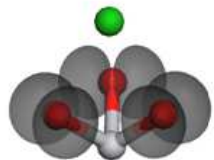

(e)
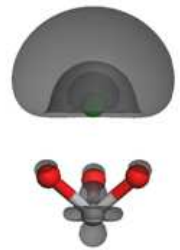

(f)

Fig. 8. The HOMO and $\mathrm{LUMO}$ orbits of $\mathrm{BaO}, \mathrm{TiO}_{2}$, and $\mathrm{BaTiO}_{3}$ molecules (color online).

(a) The HOMO of $\mathrm{BaO}$; (b) The LUMO of $\mathrm{BaO}$; (c) The HOMO of $\mathrm{TiO}_{2}$;

(d) The LUMO of $\mathrm{TiO}_{2}$; (e) The HOMO of $\mathrm{BaTiO}_{3}$; (f) The LUMO of $\mathrm{BaTiO}_{3}$ 


\subsection{Analysis Using the Frontier Orbital Theory}

The Frontier Orbital Theory considers that molecular orbitals (the highest occupied molecular orbital, or HOMO, and the lowest unoccupied molecular orbital, or LUMO) play a pivotal role during the chemical reaction. For lower $\mathrm{E}_{\mathrm{HOMO}}$, the electronic capacity to offer molecules is lower because the electrons in the orbital are steadier. We use $\mathrm{E}_{\mathrm{LUMO}}$ to describe the ability of a molecule to accept electrons. The lower it is, the better electron-acceptor it is.

Our calculations indicate that the energy of the $\mathrm{BaO}$ HOMO is $-288.44 \mathrm{~kJ} / \mathrm{mol}$ and its LUMO energy is -154.02 $\mathrm{kJ} / \mathrm{mol}$. For $\mathrm{TiO}_{2}$ the HOMO and LUMO energies are $558.31 \mathrm{~kJ} / \mathrm{mol}$ and $-352.97 \mathrm{~kJ} / \mathrm{mol}$, respectively, so that $\mathrm{E}_{\text {номо }}(\mathrm{BaO})>\mathrm{E}_{\text {номо }}\left(\mathrm{TiO}_{2}\right)$, and the $\mathrm{E}_{\text {LUMO }}(\mathrm{BaO})>$ $\mathrm{E}_{\mathrm{LUMO}}\left(\mathrm{TiO}_{2}\right)$. As a result, the $\mathrm{LUMO}$ of $\mathrm{TiO}_{2}$ can react with the $\mathrm{HOMO}$ of $\mathrm{BaO}$ because $\mathrm{BaO}$ can offer electrons and $\mathrm{TiO}_{2}$ can accept electrons. As shown in Figure 8, the main HOMO of $\mathrm{BaO}$ comes from the lone-pair electrons of the $\mathrm{O} 2 \mathrm{p}$ orbital, and the main part of the $\mathrm{TiO}_{2} \mathrm{LUMO}$ comes from the $3 \mathrm{~d}$ orbital of the $\mathrm{Ti}$ atom, indicating that the $\mathrm{O}$ atoms of $\mathrm{BaO}$ molecules will combine with the $\mathrm{Ti}$ atoms of $\mathrm{TiO}_{2}$ molecules. This conclusion is the same as the conclusion reached above. In addition, the calculated BTO HOMO and LUMO orbits are shown in Figure 8. The BTO HOMO distributed around the $\mathrm{O}$ atoms mainly form its lone-pair electrons in the $2 \mathrm{p}$ orbital, and the LUMO distributed around the $\mathrm{Ba}$ and $\mathrm{Ti}$ atoms mainly form their $5 \mathrm{~s}$ and $3 \mathrm{~d}$ orbital.

\section{Conclusion}

In our calculation, we find that $\mathrm{BaO}, \mathrm{TiO}_{2}$, and $\mathrm{BaTiO}_{3}$ molecules are the primary particle states in the early growth of BTO thin films by LMBE, with activation energies of $55.01 \mathrm{~kJ} / \mathrm{mol}, 11.81 \mathrm{~kJ} / \mathrm{mol}$, and $10.55 \mathrm{~kJ} / \mathrm{mol}$, respectively. We find that $\mathrm{TiO}_{2}$ molecules are formed first in vacuum where $\mathrm{Ba}, \mathrm{Ti}$, and $\mathrm{O}$ atoms coexist and become nucleation sites for BTO unit cell growth. Furthermore, the $\mathrm{BaTiO}_{3}$ molecule, a part of the BTO unit cell, is formed by $\mathrm{TiO}_{2}$ and $\mathrm{BaO}$ molecules. The BTO primary unit cell with a perovskite structure then evolves and grows with BTO unit cell migration growth on the substrate surface.

\section{Acknowledgements}

This research work has been supported by the National Natural Science Foundation of China (Grant Nos. 51172150 and 50942025) and the Research Program of Application Foundation of Sichuan Province, China (Grant No. 2014JY0091). We wish to acknowledge support from the Key Laboratory of advanced functional materials of Sichuan Normal University.

\section{References}

[1] C. H Ahn, K. M. Rabe, J. M Triscone, Science.303 (2004) 488-491.

[2] H. F. Cheng, T. F. Lin, C.T.Hu, I. N. Lin, J. Am. Ceram, Soc. 76(1993) 827

[3] W. Zhu, C. C. Wang, S. A .Akbar, R. Asiaie, J. Mater. Sci. 32 (1997) 4303

[4] Y. R. Li, J. L. Li, J. Zhu, Y. Zhang, H. Z. Zeng, X. H. Wei, J. L. Tang, Appl. Phys. Lett. 88 (2006) 152901

[5] Y. R. Li, J. L. Li, Y. Zhang, X. H. Wei, X. W. Deng, X. Z. Liu, J. Appl. Phys. 96 (2004)1640

[6] J. L. Li, Y. Zhang, X. W. Deng, X. Z. Liu, B. W. Tao, Y. R. Li, J. Vac. Sci. Technol. 24 (2004) 63 (in Chinese)

[7] C. Yang, Y. Yi, Y. R. Li, Comp.Mater.Sci.49 (2010) 845

[8] H.P. ohenberg, W. Hohn, Phys. Rev. B 136 (1964) 864-871

[9] N.M. Harrison, Comp. Phys. Comm. 137(2001) 59.

[10] B. Delley, Comput. Mater. Sci. 122 (2000)126

[11] B. Delley, J. Chem. Phys. 113 (2000) 7756

[12] B. Delley, J. Chem. Phys. 92 (1990) 508

[13] B. Delley, J. Phys. Chem. 100 (1996) 6107

[14] J. P. Perdew and Y. Wang, Phys. Rev., B 33 (1986) 8800

[15] J.P . Perdew and Y. Wang, Phys. Rev., B 45 (1992) 13244

[16] P. J. Hay, W. R. Wadt, J. Chem. Phys. 82 (1985) 299

[17] T. A. Halgren, W. N. Lipscomb, Chem. Phys. Lett., 49 (1977) 225

[18] N. Govind, M. Petersen, G. Fitzgerald, Comput. Mater. Sci. 28 (2003) 250

[19] H. Jonsson, Rev. Phys. Chem., 51 (2000) 623.

[20] J. T. Fermann, S. M. Auerbach, J. Chem. Phys., 112 (2000) 6787

[21] L. Monneriel, F. Lauprêtre, J. L. Halary, Adv. Polym. Sci., 187 (2005) 35 .

[22] G. Seeley, T.J. Keyes, Chem. Phys., 91(1989) 5581.

[23] J. H. Jensen, K. Morokuma, M.S. Gordon: Chem. Phys., 100 (1994)1981

[24] W. C. Robert, A. J. Melvin, B. H. William, 'Handbook of Chemistry and Physics',2nd edn, Florida, CRC Press, Inc., (1993) 